\title{
Construction and Characterization of an in-vivo Linear Covalently Closed DNA Vector Production System
}

\author{
Nafiseh Nafissi and Roderick Slavcev*
}

\begin{abstract}
Background: While safer than their viral counterparts, conventional non-viral gene delivery DNA vectors offer a limited safety profile. They often result in the delivery of unwanted prokaryotic sequences, antibiotic resistance genes, and the bacterial origins of replication to the target, which may lead to the stimulation of unwanted immunological responses due to their chimeric DNA composition. Such vectors may also impart the potential for chromosomal integration, thus potentiating oncogenesis. We sought to engineer an in vivo system for the quick and simple production of safer DNA vector alternatives that were devoid of non-transgene bacterial sequences and would lethally disrupt the host chromosome in the event of an unwanted vector integration event.
\end{abstract}

Results: We constructed a parent eukaryotic expression vector possessing a specialized manufactured multi-target site called "Super Sequence", and engineered E. coli cells (R-cell) that conditionally produce phage-derived recombinase Tel (PY54), TelN (N15), or Cre (P1). Passage of the parent plasmid vector through R-cells under optimized conditions, resulted in rapid, efficient, and one step in vivo generation of mini lcc - linear covalently closed (Tel/TelN-cell), or mini ccc-circular covalently closed (Cre-cell), DNA constructs, separated from the backbone plasmid DNA. Site-specific integration of Icc plasmids into the host chromosome resulted in chromosomal disruption and $10^{5}$ fold lower viability than that seen with the ccc counterpart.

Conclusion: We offer a high efficiency mini DNA vector production system that confers simple, rapid and scalable in vivo production of mini Icc DNA vectors that possess all the benefits of "minicircle" DNA vectors and virtually eliminate the potential for undesirable vector integration events.

Keywords: Mini DNA vectors, Linear covalently closed plasmid vector, DNA vector integration, Non-viral gene delivery, "minicircles", Bacteriophage PY54 Tel/pal recombination system, Bacteriophage N15 TelN/telRL

recombination system, Bacteriophage P1 Cre/loxP recombination system, Bacterial engineering

\section{Background}

The utility of any gene therapy strategy is defined by its balance between safety and effectiveness. While virusderived vectors offer exceptional potential to target and deliver DNA cargo with high efficiency into the target cell, viral strategies often suffer in their safety profiling. Recent viral gene therapy-related patient mortalities in clinical trials highlight some of the safety issues attributed to the use of viral gene transfer systems that include, but are not limited to unwanted immune responses to

\footnotetext{
* Correspondence: slavcev@uwaterloo.ca

School of Pharmacy, Faculty of Science, University of Waterloo, Waterloo, Ontario N2L 3G1, Canada
}

viral capsid proteins, regeneration of virulent viruses, and insertional mutagenesis [1]. In contrast, non-viral strategies based on naked, lipoplexed or polyplexed plasmid DNA (pDNA) vectors generally offer safer gene therapy, vaccine design, and drug delivery approaches. Plasmid DNA vectors are relatively easy to generate and store and offer tremendous design capacity. Several major barriers need to be considered in order to develop non-viral gene delivery systems as a therapeutic product to be safely administered in vivo. A successful transgene delivery system depends on the entrance of the DNA vector into the mammalian host nucleus and expression of the encoded transgene(s). While simple in theory, several cellular barriers must be overcome in practice. 
While travelling in the extracellular surroundings, vectors must be bio- and immuno-compatible and avoid degradation by serum nucleases and immune detection by phagocytes. Plasma nucleases digest the unprotected DNA within just a few minutes, so DNA vectors need to rapidly cross the plasma membrane of target cells. This is further complicated by the fact that the plasma membrane is composed of dense lipoprotein barriers that intrinsically inhibit efficient DNA translocation. Strategies to overcome this barrier include complexing DNA vectors with synthetic nanoparticles to form a structure similar to the plasma membrane [2] or receptormediated endocytosis; i.e. targeted liposomes [3]. However, while non-viral gene delivery techniques work toward efficiency of DNA delivery, they generally prove poor in the delivery of pDNA vectors to the nuclear compartment. Many techniques are currently being investigated to enhance levels of non-viral gene transfer by targeting vectors to the nucleus. These techniques include modification of plasmids with DNA nuclear targeting sequences (DTS), covalent linkage of nuclear localization signals (NLS) to the plasmid DNA constructs, and attachment of import receptors such as karyopherins, to vectors that promote uptake through the nuclear membrane pore complex (NPC) $[2,4,5]$. Modification of DNA with NLS-conjugates seems to result in highly efficient expression of linear, but not circular DNA, in combination with liposomal delivery vectors [6]. This difference may be attributed to charge per unit ratio of linear versus supercoiled circular DNA and provides yet another intriguing opportunity for lcc vectors [7].

In addition to the aforementioned challenges, conventional non-viral gene delivery approaches may lead to unwanted immunological responses and oncogenesis, imparted by the presence of bacterial genetic elements in plasmid DNA constructs. These include prokaryotic origins of replication, antibiotic resistance genes, as well as high-frequency immunostimulatory $\mathrm{CpG}$ motifs that activate Toll-like receptors in mammalian hosts [8]. In order to improve the immuno-compatibily and durability of plasmid DNA vectors, a new generation of DNA vectors have been constructed that exploit the bacteriophage $\lambda$ integrase (Int)-attP or P1-derived Cre-loxP sitespecific recombination systems to generate mini ccc DNA vectors [9]. These "minicircles" provide safer minimized transgene vectors by removing unwanted prokaryotic elements, thus enhancing bio- and immunocompatibility in the mammalian host [10]. The smaller size compared to the parental plasmid backbone also confers improved extracellular and intracellular bioavailability leading to efficient gene delivery and hence, improved gene expression [11].

A second group of modified vectors offering great promise are linear covalently closed (lcc) plasmid DNA vectors. Aside from the obvious topological differences, lcc double-stranded DNA molecules are torsion-free as they are not subject to gyrase-directed negative supercoiling, and as such possess the properties of linear DNA [12]. However, lcc DNA is not subject to ExoV exonuclease activity in prokaryotes due to covalent linkage of linear ends, preventing degradation of the lcc pDNA vector. Lcc DNA vectors have been constructed by various in vitro strategies including the capping of PCR products, and the "minimalistic immunogenic defined gene expression (MIDGE)" vectors. MIDGE is generated by the digestion of both prokaryotic and eukaryotic backbones after isolation of plasmid from bacterial cells, followed by ligation of the therapeutic expression cassette into hairpin sequences for end-refilling [13]. This technology has shown promising results in various applications including the development of a Leishmania DNA vaccine [14] and a colon carcinoma treatment [15]. MIDGE vectors have also demonstrated up to 17 fold improved transgene expression profile in vivo in some tissues, compared to conventional plasmid DNA vectors [16]. Thus, lcc DNA vectors may in fact outperform their circular counterparts with respect to expression efficiency and bioavailability. However, large-scale production of lcc DNA vectors via existing multistep in vitro processes requires considerable time and financial cost.

E. coli phage $\mathrm{N} 15$ was the first discovered phage to exist in its lysogenic (prophage) state as a linear covalently closed (lcc) plasmid [17] that is actively partitioned to daughter cells [18]. The lcc conformation is conferred by the cleaving-joining activity of the protelomerase protein (Prokaryotic Telomerase), TelN ( $72 \mathrm{kDa})$, acting upon the $56 \mathrm{bp}$ telRL target sequence that is entirely sufficient to confer TelN-mediated processing and linearization both in vivo and in vitro $[19,20]$. Similarly, phage PY54, isolated from Yersinia enterocolitica, maintains its prophage as a linear, circularly permuted, and covalently closed plasmid with telomere hairpin ends and a genome size of $46 \mathrm{~kb}$. The paralogous minimal protelomerase target site of PY54 is a 42 bp perfect palindrome that unlike $\mathrm{N} 15$, only partially functions in vivo in the absence of adjacent sequences [21]. The paralogue of the N15 TelN protelomerase, Tel, encodes a $77 \mathrm{kDa}$ protein with observably identical function, able to process recombinant plasmids containing the pal, 42 bp palindromic target site [21]. The tel gene possesses $60 \%$ sequence identity to telN and the active recombinases are similar in size $(\sim 77 \mathrm{kDa})$. In addition, there is a partial homology between the 42 bp PY54 pal site and the 56 bp N15 telRL site, where the ten central palindromic nucleotides (5'-TACGCGCGTA-3') are identical [21]. Despite obvious similarities between the two phages they are evolutionary quite distant, where N15 is more 
closely related to $\lambda$ than to PY54. Purified TelN was shown to process circular and supercoiled plasmid DNA containing the identified target site, telRL, to produce linear double-stranded DNA with covalently closed ends. The lcc and mini lcc DNA vectors produced in vitro by recombinant TelN have been successfully applied in gene delivery experiments, and showed higher and more durable expression of the gene of interest in targeted human cells $[20,21]$. In contrast, to the best of our knowledge, there are no reported applications of the Tel-pal system. Furthermore, current TelN-telRL applications are based on recombinant TelN production for in vitro lcc DNA vector generation [22]. In this study, we report for the first time the development and characterization of an optimized in vivo mini lcc DNA production platform, exploiting the Tel-pal and TelN-telRL recombination systems. This one-step production system combines the biocompatibility benefits of "minicircles" with the transfection efficiency and safety profile of "MIDGE".

\section{Results}

R-cells exhibit temperature-regulated recombinase expression

Recombinant E. coli cells (R-cells) were constructed that place tel or telN recombinase genes under control of the bacteriophage $\lambda$ strong promoter, $p L$, that is regulated by the temperature-sensitive $\lambda$ repressor, $\mathrm{CI}[\mathrm{Ts}] 857$ (Figure 1A). We also similarly constructed cre-expressing cells to serve as a positive control, where in vivo Cre-loxP activity is well documented $[23,24]$. We examined total cellular protein in tel and telN R-cells under repressed $\left(30^{\circ} \mathrm{C}\right)$ and fully induced $\left(42^{\circ} \mathrm{C}\right)$ conditions (Figure 1B). As expected, both R-cells demonstrated minimal recombinase protein levels, identified at $72 \mathrm{kDa}$ for both TelN and $\mathrm{Tel}$ at $30^{\circ} \mathrm{C}$, where $\mathrm{CI}[\mathrm{Ts}]$ actively binds the $o L$ operator and represses transcription of the downstream recombinase gene. Upon shifting cells to $42^{\circ} \mathrm{C}$, where repressor activity is completely abrogated and occlusion of $p R$ and $p L$ promoter activity is relieved, prominent

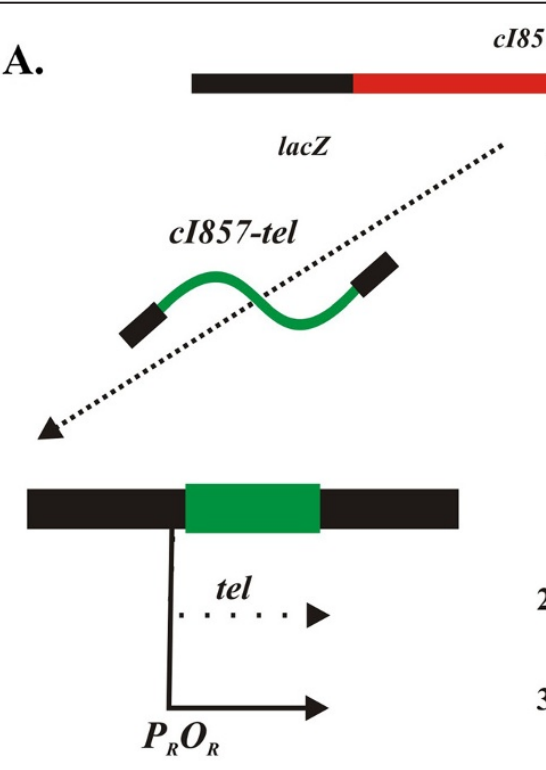

Tel-cell $25-30^{\circ} \mathrm{C}$

$39-42^{\circ} \mathrm{C}$

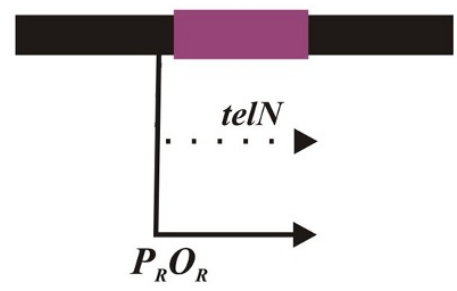

TelN-cell

B.

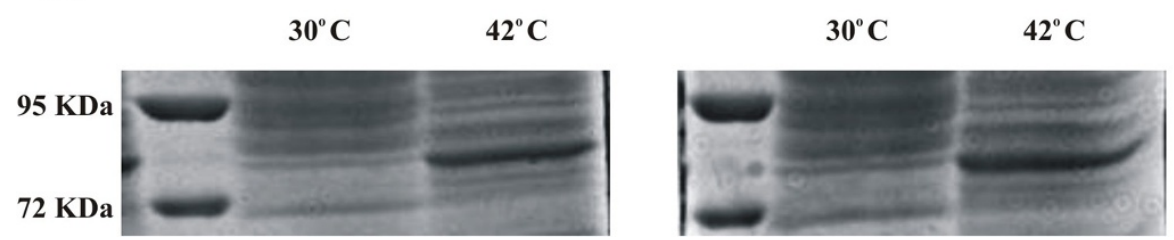

Figure 1 R-cell construction and temperature-regulated expression of Tel and TeIN. A. R-cell construction and temperature-regulated expression of recombinases, Tel and TelN. The cl857-R cassette was inserted into the lacZ gene of E. coli by homologous recombination. Under repressed $\left(25-30^{\circ} \mathrm{C}\right)$ conditions, the $\lambda$ temperature-sensitive Cl857 repressor binds to $\lambda$ operators to inhibit transcription of the recombinase gene, but upon shifting to $40-42^{\circ} \mathrm{C}$, the repressor is denatured, falling off the operators and induces expression of the recombinase from the strong $\lambda$ $p L / p R$ promoter. B. Controllable Tel and TelN expression from R-cells. Expression of the recombinase proteins Tel and TelN under repressed $\left(30^{\circ} \mathrm{C}\right)$ and induced $\left(42^{\circ} \mathrm{C}\right)$ conditions from total R-cell extract. Lane 1: Weight marker; Lane 2: Recombinase. 
recombinase expression was observed. These results confirm that the constructed $\mathrm{Tel}^{+}$and Tel-N $\mathrm{N}^{+}$cells are temperature inducible for recombinase production.

In combination with the R-cell system, we next constructed a eukaryotic egfp-expression plasmid DNA vector that carries two specialized $343 \mathrm{bp}$ sequences placed upstream of the SV40 promoter and downstream of the polyadenylation signal of the minimal egfp expression cassette (pNN9; Figure 2A). This construct, termed "Super Sequence" (SS) carries a modified pal target sequence of Tel, with integrated telRL (TelN), loxP (Cre) and FRT (Flp) sequences in non-binding regions of pal sequence, and SV40 enhancer sequences that flank pal on either side to enhance nuclear translocation (Figure 2B). The rationale behind the multi-target sequence composition of SS was to allow the same parent plasmid vector to be passed through different R-cells to generate either mini lcc or mini ccc conformation of the minimal expression cassette. We employed the pNN9 $(5.6 \mathrm{~kb})$ plasmid to confirm that controlled production of recombinase from R-cells was associated with controllable recombinase enzymatic activity, by examining the ability of R-cells to convert plasmids carrying the SS sites to the appropriate mini lcc (Tel or TelN) or mini ccc (Cre) conformation. The $\mathrm{SS}^{+}$-derivative (pNN9; Table 1) was passaged through $\mathrm{Tel} / \mathrm{TelN}^{+}$or $\mathrm{Cre}^{+} \mathrm{R}$-cells at optimized conditions and assessed formation of mini lcc or mini ccc DNA vectors during the one-step in vivo processing and amplification protocol (Figure 3A). By flanking the gene of interest (GOI) expression cassette with two SS sites, we expected to excise the GOI $(2.4 \mathrm{~kb})$ for easy separation from the remaining prokaryotic backbone $(3.2 \mathrm{~kb})$ parental DNA, including the origin of replication and $A p^{R}$ marker at temperatures inducing recombinase expression (Figure 3B). Recombinase activity on pNN9 was evident when the plasmid was processed at $42^{\circ} \mathrm{C}$ where R-cell recombinase expression was "on". No $\mathrm{SS}^{+}$plasmid processing was evident at $30^{\circ} \mathrm{C}$ when expression was "off", or with the $\mathrm{SS}^{-}$control plasmids under all

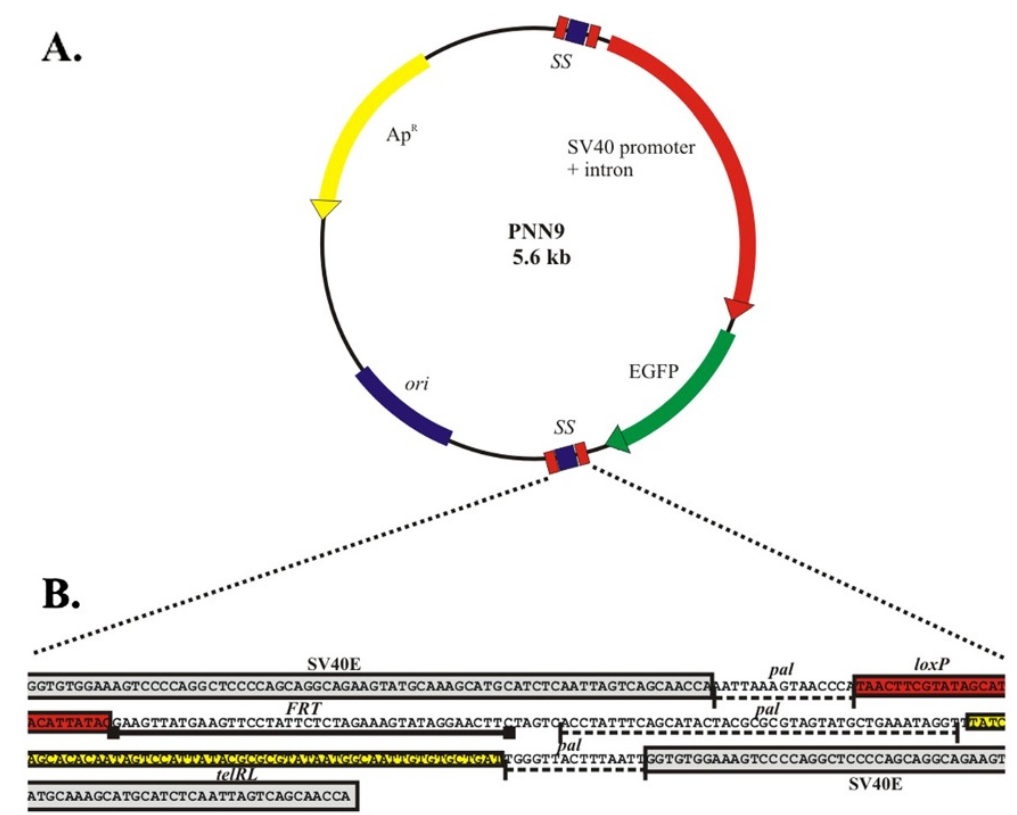

\begin{tabular}{lcc}
\multicolumn{1}{r}{ Target sequence } & Start & End \\
\hline SV40E & 1 & 72 \\
pal & 73 & 87 \\
loxP & 88 & 120 \\
FRT & 121 & 154 \\
pal & 160 & 201 \\
telRL & 203 & 256 \\
pal & 257 & 271 \\
SV40E & 272 & 343 \\
\hline
\end{tabular}

Figure 2 Parent plasmid pNN9 and "Super Sequence" multi-target site. A. Map of the parent pNN9 construct. The map denotes location of primary genetic elements, including the designed and integrated Super Sequence (SS). B. Map of the Super Sequence construct. The map includes relative locations of SV40 enhancer sequences as well as the telRL, loXP and FRT sequences integrated into non-binding regions of the 142 bp pal target site (Tel). 
Table 1 Bacteria, Phage and Plasmids

\begin{tabular}{|c|c|c|}
\hline Strain & Genotype or description & Source \\
\hline \multicolumn{3}{|l|}{ Bacteria } \\
\hline BW23474 & $\begin{array}{l}\text { F-, } \Delta \text { (argF-lac) 169, } \Delta \text { uidA4:::pir-116, recA1, rpoS396(Am), endA9(del-ins)::FRT, rph-1, } \\
\text { hsdR514, rob-1, creC510 }\end{array}$ & E. coli Genetic Stock Center (CGSC) \# 7838 [39] \\
\hline $\mathrm{DH} 5 \mathrm{a}$ & $\begin{array}{l}\text { F-, } \Delta(\operatorname{argF-lac}) 169, \varphi 80 \mathrm{~d} l a c Z 58(\mathrm{M} 15), \Delta p h o A 8, \text { glnV44(AS), } \lambda \text {, deoR481, rfbC1, gyrA96 } \\
\text { (NalR), recA1, endA1, thi-1, hsdR17 }\end{array}$ & CGSC \# 12384 \\
\hline DH5a $\lambda$ pir & $\mathrm{F}-, \Delta(\arg F-$ lac $) 169$, endA1, pir ${ }^{+}$, recA1 & Gift from Dr. T. Charles; [40] \\
\hline JM109 & $\begin{array}{l}\text { F', } \Delta(g p t-l a c) 0, \text { glnV44(AS), } \lambda \text {, rfbC1, gyrA96(NalR), recA1, endA1, spoT1?, thi-1, hsdR17, } \\
\text { pWM5, F128-x }\end{array}$ & New England Biolabs \\
\hline W3101 & $F-, \lambda$, galT22, IN(rrnD-rrnE) 1, rph-1 & CGSC \# 4467; \\
\hline W3110 & $\mathrm{F}-, \lambda^{-}$, IN(rrnD-rrnE) 1, rph-1 & CGSC \# 4474;[41] \\
\hline $\begin{array}{l}\text { W3110-Cre } \\
\text { (W1NN) }\end{array}$ & F-, $\lambda^{-}$, IN(rrnD-rrnE)1, rph-1 lacZ:: cat-cl857-cre $\left(\mathrm{Cm}^{\mathrm{R}}\right)$ & This study \\
\hline $\begin{array}{l}\text { W3110-TelN } \\
\text { (W2NN) }\end{array}$ & F-, $\lambda^{-}$, IN(rrnD-rrnE)1, rph-1 lacZ::cat-cl857-telN $\left(\mathrm{Cm}^{\mathrm{R}}\right)$ & This study \\
\hline $\begin{array}{l}\text { W3110-Tel } \\
\text { (W3NN) }\end{array}$ & $\mathrm{F}-, \lambda$, IN(rrnD-rrnE)1, rph-1 lacZ::cat-cl857-tel $\left(\mathrm{Cm}^{\mathrm{R}}\right)$ & This study \\
\hline \multicolumn{3}{|l|}{ Phages } \\
\hline N15 & Wild type (wt) $\left(t e / N^{+}\right.$, tos $\left.^{+}\right)$ & Gift from Dr. S. Hertwig; [21] \\
\hline P1 & wt $\left(\mathrm{cre}^{+}\right.$, lox $\left.\mathrm{P}^{+}\right)$ & Gift from Dr. B. Funnell; [42] \\
\hline PY54 & wt $\left(t e l^{+}, p a l^{+}\right)$ & Gift from Dr. S. Hertwig; [21] \\
\hline \multicolumn{3}{|l|}{ Plasmids } \\
\hline pAH120 & attP $\lambda$ integration plasmid $\left(\mathrm{Kn}^{\mathrm{R}}\right)$ & NBRP [25] \\
\hline pAH123 & c1857-pL-int $\Phi 80\left(\mathrm{Ap}^{\mathrm{R}}\right)$ & NBRP [25] \\
\hline pAH153 & attP $\Phi 80$ integration plasmid $\left(\mathrm{Kn}^{\mathrm{R}}\right)$ & NBRP [25] \\
\hline pBRINT & lacZ::cat-MCS::lacZ $\left(\mathrm{Cm}^{\mathrm{R}}\right)$ & NBRP; [37] \\
\hline pGL2 & SV40P-Luc-PolyA-SV40 intron & Promega \\
\hline plnt(ts) & c1857-pL-int $\lambda\left(A p^{R}\right)$ & NBRP [25] \\
\hline pNN1 & c1857-pR-pL-cre-tL $\left(A p^{R}\right)$ & This study \\
\hline pNN2 & $c 1857-p R-p L-t e l-t L\left(A p^{R}\right)$ & This study \\
\hline pNN3 & c1857-pR-pL-te/N-tL $\left(\mathrm{Ap}^{\mathrm{R}}\right)$ & This study \\
\hline pNN4 & lacZ::cat- c1857-pR-pL-cre-tL::IacZ $\left(\mathrm{Cm}^{\mathrm{R}}\right)$ & This study \\
\hline pNN5 & lacZ:: cat-c1857-pR-pL-tel-tL::IacZ $\left(\mathrm{Cm}^{\mathrm{R}}\right)$ & This study \\
\hline pNN6 & lacZ::cat-c1857-pR-pL-telN-tL::IacZ $\left(\mathrm{Cm}^{\mathrm{R}}\right)$ & This study \\
\hline pNN7 & pGL2-egfp switched for luc & This study \\
\hline pNN8 & pNN7 + SS (upstream of SV40 promoter) & This study \\
\hline pNN9 & pNN8-SS (2SS) (second SS downstream of SV40 polyA sequence) & This study \\
\hline pNN10 & $\mathrm{pAH} 120\left(\mathrm{SS}^{+}\right)$ & This study \\
\hline pNN11 & $\mathrm{pAH} 153\left(\mathrm{SS}^{+}\right)$ & This study \\
\hline pPL451 & c1857-pR-pL-MCS-tL $\left(A p^{R}\right)$ & $\begin{array}{l}\text { Accession \# AB248919 National Bioresource } \\
\text { Project (NBRP); [43] }\end{array}$ \\
\hline
\end{tabular}

tested conditions (data is not shown). Optimal linearization conditions for pNN9 were conducted in both $\mathrm{Tel}^{+}$and $\mathrm{TelN}^{+}$cells and pNN9 processed products were extracted and analyzed. During the optimization process, different thermal conditions were tested to determine the ideal induction stage during R-cells growth and the induction duration that generates maximum recombinase production and plasmid processing. We found that shifting the temperature at late logarithmic phase to $42^{\circ} \mathrm{C}$ for 30 min to induce R-cells conferred optimal recombinase expression and plasmid processing. In all cases, extracted mini lcc DNA vectors behaved with equivalent stability in storage and manipulation to their ccc counterparts or parental plasmid DNA (data not shown). Linearization of pNN9 and extraction of the mini lcc vector, was also much more efficient in $\mathrm{Tel}^{+}$, as compared to the $\mathrm{TelN}^{+}$counterpart (Figure $3 \mathrm{C}$ ). These findings indicate that $\mathrm{Tel}$ is active upon $\mathrm{pal}^{+}$constructs 


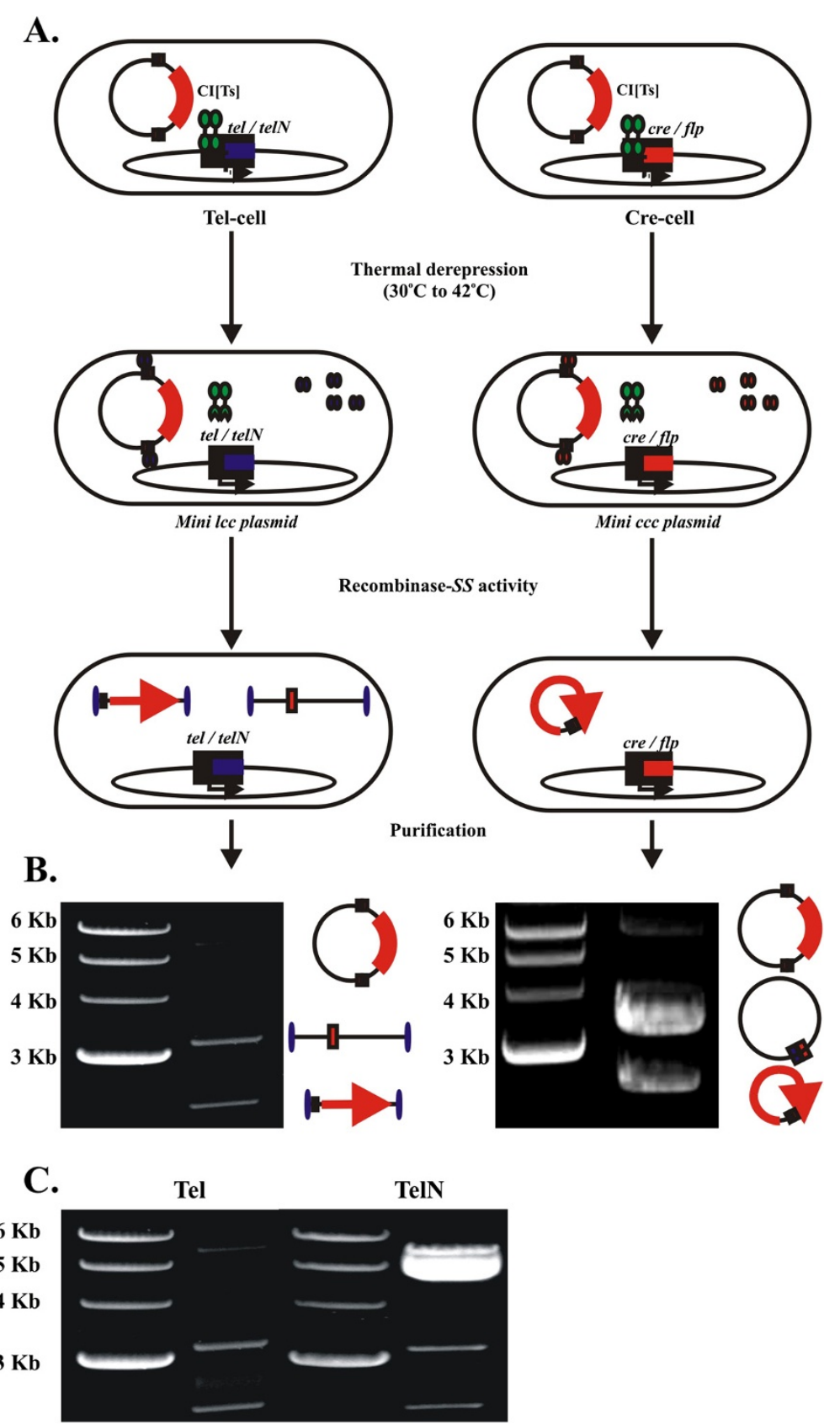

Figure 3 Conditional processing of the parent plasmid DNA vectors. A. R-cell conditional processing of the parent pNN9 plasmid into mini vectors. Under induced conditions, R-cells lead to the production of mini Icc (TelN- or Tel-cell) and mini ccc (Cre-cell) DNA vectors by recombinase activity on its target site encoded within the 2 Super Sequence sites on pNN9. Processing of the parent plasmid DNA results in production of two species - the mini DNA vector and the mini plasmid backbone. B. Processing of the parent plasmid construct into mini Icc and mini ccc vectors. Efficiency of processing of the pNN9 plasmid into mini Icc DNAs (Tel) and "minicircles" (Cre) after plasmid extraction from R-cells under induced $\left(42^{\circ} \mathrm{C}\right)$ conditions. Schematics adjacent to each bands show the DNA constructs and expected conformation. C. In vivo Tel-pal recombination efficiency versus TelN-telRL. Efficiency of processing of the pNN9 plasmid into mini Icc DNA vectors in Tel ${ }^{+}$versus TelN ${ }^{+}$R-cells.

in vivo and that the modification of pal target site through the addition of loxP, FRT, and telRL minimal target sequences into non-binding regions of the full 142 bp pal target site does not abrogate Tel-pal functionality.
Integration of Icc DNA vector into the chromosome results in loss of cell viability

We asked whether a single crossover recombination event integrating a linear pDNA vector with covalently closed ends into a host cell chromosome would disrupt 
the chromosome and kill the cell (Figure 4). To assess the outcome of linearizing the E. coli chromosome by lcc DNA integration, we employed an in vivo approach by exploiting $\lambda$ and $\Phi 80$ Int-att site-specific recombination systems [25] in a $\operatorname{Rec}^{+}$background. To target the chromosome, an integrating plasmid vector that carries the $\lambda$ attP target site of the $\lambda$ integrase and an R6K origin was used as it is only capable of replication in the presence of $\pi$ protein (encoded by pir gene), which is absent from all R-cells. As such, the plasmid is either integrated or rapidly lost from the growing R-cell population. An SS was incorporated into the integrating pDNA vector to change plasmid conformation from ccc to lcc in the presence of TelN or Tel in R-cells. Using this system we sought to assess integration efficiency following transformation of parent, $\mathrm{Tel}^{+}$or $\mathrm{TelN}^{+} \mathrm{R}$ cells by $\mathrm{SS}^{-}$and $\mathrm{SS}^{+}$integrating plasmid vectors under conditions induced or repressed for recombinase expression in R-cells. A ccc $\lambda$ or $\Phi 80$ att $P^{+} \mathrm{SS}^{+}$plasmid that is taken up by the cell expressing $\lambda$ or $\Phi 80 \mathrm{int}$, respectively, and producing Tel or TelN, should be altered from ccc to lcc conformation. Upon Int-mediated attspecific chromosomal integration, the recombination of lcc should disrupt the chromosome. And, as unintegrated plasmids are incapable of replication, they would be rapidly lost from the cell population.

The integration frequency (IF) of $\lambda$ attP $\mathrm{SS}^{+}$integrating plasmids into induced $\mathrm{Tel}^{+} \mathrm{R}$-cells was more than $10^{5}$-fold lower than that seen for the $\mathrm{SS}^{-}$counterpart or the $\mathrm{SS}^{+}$integrating plasmids in parent W3110 cells (Table 2). TelN ${ }^{+}$R-cells did not demonstrate nearly as strong an effect, whereby IF compared to the wild type cells was 50 -fold lower, and only 25 -fold lower versus integration of the $\mathrm{SS}^{-}$derivative. We further studied up to 20 survivor isolates from both $\mathrm{TelN}^{+}$and $\mathrm{Tel}^{+}$cells by
PCR for evidence of chromosomal linearization, and found that $100 \%$ of tested survivors possessed intact (unlinearized) plasmid. These findings are likely due to the a higher efficiency of Tel-pal system in formation of a lcc product as compared to TelN acting on the minimal telRL target site encoded within the SS. Although we attempted to repeat this experiment using a constructed $\Phi 80$ attP $\mathrm{SS}^{+}$integrating pDNA vector by the R-cells expressing $\Phi 80 \mathrm{int}$, we found that integration frequencies were lower across all tested cells.

We next sought to investigate chromosomal linearization by constructing $\mathrm{SS}^{+}$or $\mathrm{SS}^{-}$integrants using the same $\lambda$ and $\Phi 80$ Int-attP plasmid integration system. Unlike the previous experiment, this time, rather than assessing the number of integrants formed in the presence of the linearizing recombinase, we first stably integrated the plasmid into the chromosome before inducing recombinase expression. Cells carrying the integrated $\mathrm{SS}^{+}$or $\mathrm{SS}^{-}$vector were maintained under repressed tel and telN conditions $\left(30^{\circ} \mathrm{C}\right)$ and several isolates were assessed for integration of single versus multiple copies of plasmid by PCR. In all cases, single integration events represented the majority of recombinants for both $\mathrm{SS}^{+}$and $\mathrm{SS}^{-} \lambda$ or $\Phi 80$ attP integrating plasmids (56.5-100\%). Multiple copy integrants were not studied further and discarded.

To determine the fate of cells upon linearizing/disrupting the $E$. coli chromosome, we incubated $\lambda$ site-specific $\mathrm{SS}^{-}$and $\mathrm{SS}^{+}$integrants under conditions that provide no to very low, or fully derepressed expression of the recombinase at $30^{\circ} \mathrm{C}$ and $42^{\circ} \mathrm{C}$, respectively, and then measured cell viability (Table 3 ). Under repressed conditions $\left(30^{\circ} \mathrm{C}\right)$, all recombinant cells retained near full viability regardless of the presence or absence of the SS integrated in the chromosome. However, upon shifting
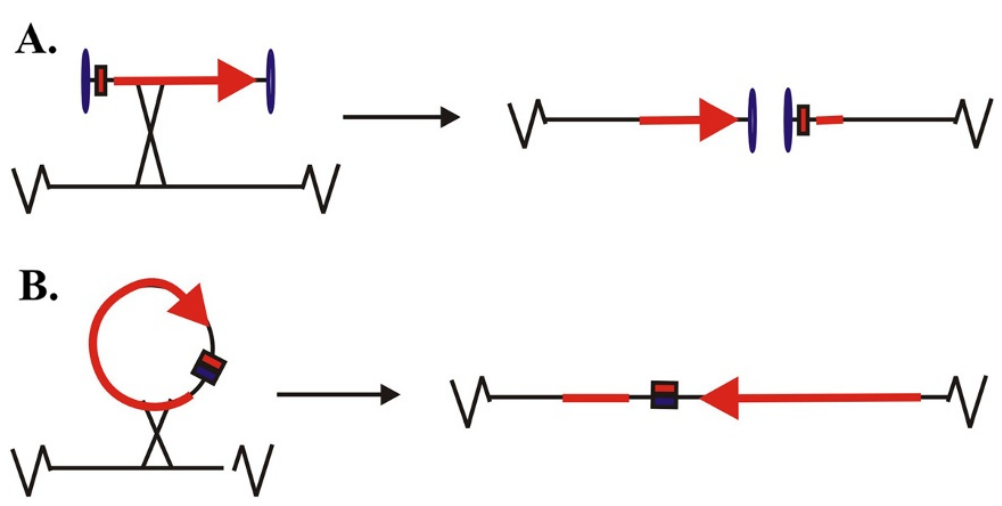

Figure 4 Schematic representations of linear and circular vector integration events. A mini vector that undergoes a single recombination event with the host chromosome is rare due to the removal of all elements except the cistron containing the GOl expression cassette and the flanking Super Sequence sites. A. Lcc plasmid DNA vector integration event would result in chromosomal "break" at the site of integration, whereby the chromosome cannot be replicated or segregated and the integrated mammalian cell cannot divide due to separation of centromere from telomere. B. A "minicircle" vector can integrate into a non-essential region of the host chromosome without "breaking" the chromosome, whereby the cell is able to continue dividing with the insertion. 
Table 2 Linear covalently closed (Icc) plasmid confers reduced integration frequency

\begin{tabular}{lll}
\hline R-cell $^{1}$ & ${\text { Plasmid SS }(+/-)^{2}}^{\mathbf{2}}$ & Integration Frequency $^{3}$ \\
\hline Cre & - & 0.76 \\
Cre & + & 0.005 \\
TelN & - & 0.51 \\
TelN & + & 0.02 \\
Tel & - & 1.0 \\
Tel & + & $1.03 \times 10^{-5}$ \\
\hline
\end{tabular}

${ }^{1}$ R-cells are all W3110 derivatives expressing recombinase gene at $42^{\circ} \mathrm{C}$ the recombinase gene is fully induced. R-cells carry the $\lambda$ int expression plasmid pAH153.

2 pAH120 plasmid carrying $\lambda$ attP.

${ }^{3}$ Mean of minimum 3 trials. IF is expressed as fraction of integration frequency of parent strain, W3110.

temperature to $42^{\circ} \mathrm{C}$ and inducing expression of Tel or TelN, recombinants that carried $\mathrm{SS}^{+}$showed dramatically reduced viability. And, in both systems, Tel-cells resulted in approximately 5 -fold greater killing than that seen in TelN-cells. Interestingly, the killing effect of $\mathrm{SS}^{+}$ plasmid in $\Phi 80$ attB site was about 10 -fold lower than was observed when integrated into $\lambda$ attB site. This finding suggests that positioning of the attB site may influence the viability of cells with a linear chromosome.

\section{Visualization of Cells upon induction}

Wild type and Tel-cells carrying chromosomally inserted $\mathrm{SS}^{+}$or $\mathrm{SS}^{-}$integrating plasmid vectors were gram stained and visualized under repressed $\left(30^{\circ} \mathrm{C}\right)$ versus induced $\left(42^{\circ} \mathrm{C}\right)$ conditions for tel recombinase expression to investigate cell morphology as a result of chromosomal disruption (Figure 5). At $42^{\circ} \mathrm{C}$, only SS${ }^{+}$ $\mathrm{Tel}^{+}$integrants demonstrated a highly contracted and irregular morphology compared to $\mathrm{SS}^{-}$cells, or $\mathrm{SS}^{+}$ cells grown at $30^{\circ} \mathrm{C}$, repressed for tel expression. We

Table 3 Recombinase-mediated linearization of the chromosome results in cell killing

\begin{tabular}{|c|c|c|c|c|}
\hline \multirow{2}{*}{$\begin{array}{l}\mathrm{R}- \\
\text { cell }{ }^{1}\end{array}$} & \multirow{2}{*}{\multicolumn{2}{|c|}{$\begin{array}{l}\text { Integrated } \\
\text { plasmid SS } \\
(+/-)^{2}\end{array}$}} & \multicolumn{2}{|c|}{ Cell viability following induction ${ }^{3}$} \\
\hline & & & $30^{\circ} \mathrm{C}$ & $42^{\circ} \mathrm{C}$ \\
\hline TelN & - & $\lambda$ & 0.8 & 0.6 \\
\hline TelN & + & $\lambda$ & 1.0 & $5.7 \times 10^{-4}$ \\
\hline TelN & - & $\Phi 80$ & 0.8 & 0.4 \\
\hline TelN & + & $\Phi 80$ & 1.0 & $5 \times 10^{-3}$ \\
\hline Tel & - & $\lambda$ & 1.0 & 1.0 \\
\hline Tel & + & $\lambda$ & 1.0 & $1.3 \times 10^{-4}$ \\
\hline Tel & - & $\Phi 80$ & 1.0 & 0.8 \\
\hline Tel & + & Ф80 & 1.0 & $1.1 \times 10^{-3}$ \\
\hline
\end{tabular}

${ }^{1}$ R-cells are all W3110 derivatives cured of pAH153 plasmid during construction stage and confirmed for single integration event by PCR.

${ }^{2}$ pAH120 plasmid carrying $\lambda$ attP grown and prepared under minimal inducing conditions $\left(30^{\circ} \mathrm{C}\right)$.

${ }^{3}$ Average of minimum 3 trials. Viability is expressed as a fraction of colonies counted under non-induced $\left(25^{\circ} \mathrm{C}\right)$ conditions. screened $10 \mathrm{Tel}^{+} / \mathrm{SS}^{+}$colonies that grew at $42^{\circ} \mathrm{C}$, for linearization by PCR and found that all of the colonies showed an unlinearized $\mathrm{SS}^{+}$plasmid insert (data not shown). Surviving colonies were however, very small compared to their $\mathrm{SS}^{-}$counterpart or the wild type parent, and retained this morphology whether grown under inducing or repressed conditions. We averaged the length of 400 randomly selected cells. We noted that the $\mathrm{SS}^{-}$controls were similar at both $30^{\circ}$ and $42^{\circ} \mathrm{C}$ with a normal average length for log phase $E$. coli in rich medium, measuring $3.9 \pm 0.4$ and $3.9 \pm 0.6 \mu \mathrm{m}$ respectively. In contrast, cells, possessing the chromosomally integrated SS site, were much smaller at $42^{\circ} \mathrm{C}$, where tel expression was fully induced, and averaging only $1.2 \pm 0.2 \mu \mathrm{m}$ in length. In contrast, a small proportion of these cells $(1.5 \%)$ were filamentous. This may be attributed to replication delay or inhibition in these cells. Under the conditions where we would expect chromosomal disruption, we also observed a great deal of cellular debris. At $30^{\circ} \mathrm{C}$, where tel expression was repressed, cells were considerably larger at $3.0 \pm 0.8 \mu \mathrm{m}$ but there was a much greater variability in size between cells ranging from 1.2 to $4 \mu \mathrm{m}$. This variability could be the consequence of leaky expression of tel due to incomplete repression of the $\mathrm{CI}[\mathrm{Ts}] 857$ repressor at $30^{\circ} \mathrm{C}$.

\section{Discussion}

To date, mini DNA vector production has been limited to in vitro strategies, adding expense and complexity to the developmental process, particularly in scalability. The mini DNA vector production system, described here, is an in vivo platform to generate high quality bacterial sequence-free mini DNA vectors in both lcc and ccc topology. Modified mini vectors can be purified directly from our engineered $E$. coli cells (R-cells) using standard plasmid isolation methods, and without the need for digestion, ligation, and gel purification. To generate R-cells, we flanked the $c I[\mathrm{Ts}] 857$-protelomerase expression cassettes by homology to lac $Z$ gene and recombined the cassette into $\mathrm{rec}^{+} \mathrm{W} 3110 \mathrm{E}$. coli cells screening for $\mathrm{Lac}^{-}$colonies. R-cells were designed and optimized to chromosomally encode specific recombinases under control of a strong $\lambda p L$ promoter. However, since strong promoters impart metabolic burden on the host cell, where protein production may occur at the expense of cell growth [26], we employed a simple thermally-regulated promoter system that circumvents any potential toxicity, metabolic stress or recombinase interference that might arise from the use of chemicalmediated induction strategies. As such we were able to optimize the production of mini DNA vectors through simple control over manufacture temperature using the $\lambda \mathrm{CI}[\mathrm{Ts}] 857 o L-p L$ expression system [27]. Various modifications to our parent vector construct by simple 


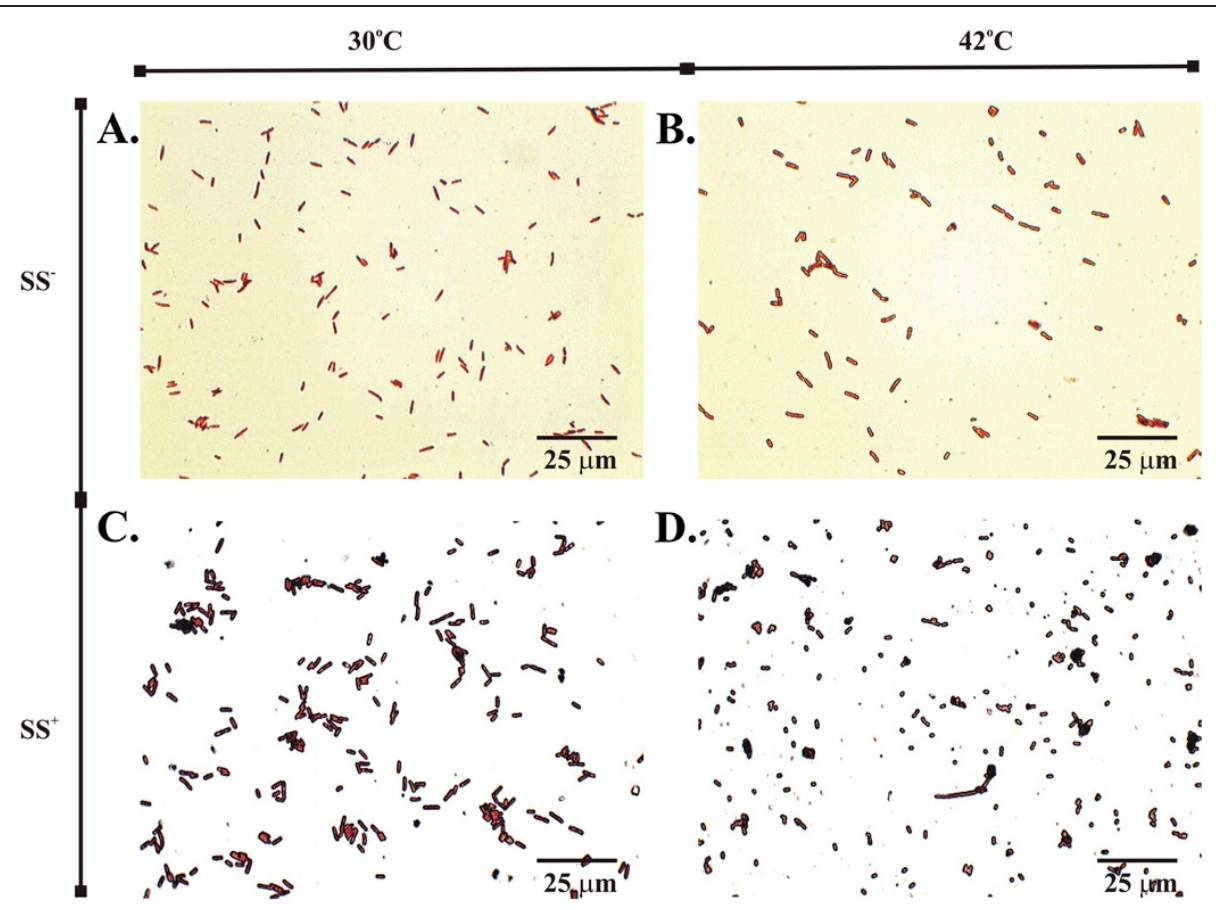

Figure 5 Effect of Tel-mediated chromosomal disruption on cell morphology. Tel-mediated disruption of the host chromosome results in a contracted cellular morphology. Tel ${ }^{+} \mathrm{R}$-Cells possessing an integrated plasmid that was $\mathrm{SS}^{+}\left(\mathrm{pal}^{+}\right.$) or $\mathrm{SS}^{-}$(pal) ) were grown in $\mathrm{LB}$ media at $30^{\circ} \mathrm{C}$ (no Tel production) to early log phase $A_{600}=0.2$, then were divided in two tubes and grown separately at $30^{\circ} \mathrm{C}$ or $42^{\circ} \mathrm{C}$ to reach to late log phase $A_{600}=0.8$. Bacterial smears were then prepared on the slide and heat fixed and gram stained. Pictures of bacteria were taken at $1000 \mathrm{X}$ magnification. A. SS integrants at $30^{\circ} \mathrm{C}$ where tel expression is repressed; $\mathbf{B}$. SS $S^{-}$integrants at $42^{\circ} \mathrm{C}$ where tel is induced but the pal target site is absent; $\mathbf{C}$. SS integrants at $30^{\circ} \mathrm{C}$ where pal target site is present but tel expression is repressed; $\mathbf{D}$. SS ${ }^{+}$integrants at $30^{\circ} \mathrm{C}$ where tel is induced and present to act on the chromosomally integrated pal target site.

passaging through different R-cells was made possible by the insertion of the unique multi-target sequence (Super Sequence) described for the first time here. The Super Sequence inserts the cleave-joining multi-target site for TelN, Cre, and Flp enzymes within the non-coding regions of the $142 \mathrm{bp}$ minimal sequence of pal site required for in vivo processing by Tel [21]. The retained activity of Tel in processing this site indicates that the replacement of non-coding regions within the pal sequence of PY54 does not compromise cleavejoining activity of the Tel-pal system.

Mini linear covalently closed (lcc) DNA vectors, devoid of parental prokaryotic genetic elements were successfully generated in vivo exploiting the bacteriophage PY54-derived protelomerase recombination system. The mini vector produced via this system is a stable linear DNA expression cassette with covalently closed ends. Application of pDNA vectors in naked, lipoplexed, or polyplexed form for gene transfer conventionally employs plasmid vectors designed either to administer genes coding for therapeutic proteins, antigens, or antibodies into a given organism; or introduce a correct gene into a host cell to replace the mal- or nonfunctional allele [28]. Derived from conventional plasmid DNA vectors, bacterial sequence-free mini DNA derivatives provide superior alternatives to traditional plasmid vectors, with some advancing in clinical trials [29]. Conventional plasmid vectors carry a bacterial backbone in addition to the cistron expressing the gene of interest (GOI) in addition to necessary regulatory elements such as the promoter, enhancer, intron, and polyA terminal sequence. While necessary for amplification and maintenance in the prokaryotic host, the plasmid vector backbone carries prokaryotic genetic elements, including antibiotic resistance gene(s) and an origin of replication. It was previously shown that antibiotic resistance genes are undesirable for administration to human body due to potential adverse effects and events such as their horizontal gene transfer imparting resistance to naturally occurring mammalian host flora; and their compromising effect on GOI expression [30]. CpG motifs, 20 times more common in prokaryotic DNA, induce polygonal B-cell activation and activate Toll-like receptors that in addition to generating potentially unwanted immunostimulatory responses, may also reduce or abrogate transgene expression [30,31].

Bacterial sequence-free mini DNA vectors provide better bioavailability compared to conventional plasmid DNA vectors due to their smaller size and higher immuno-compatibility due to reduced or eliminated 
unwanted immune responses. Their smaller size confers higher transfection efficiency and higher copy numbers of the vector per unit mass, resulting in lower toxicity due to the need for less transfection reagents. Smaller pDNA vectors also better resist shear forces associated with the in vivo administration and delivery to the target site [32], important improvements to safety and efficiency of transgene delivery in treatment of human disease [33].

Conventional plasmid vectors are extra-chromosomal, circular, covalently closed, double-stranded DNA molecules that often possess elements or sequences such as viral promoters or cloned coding sequences that could subject them to unwanted recombination events [34]. A major safety concern associated with gene delivery, whether by viral or non-viral carriers, is the potential for integration of plasmid DNA into the host chromosome. Integration events that activate proto-oncogenes and/or deactivate tumor suppressor genes may result in oncogenesis or silencing of adjacent genes [35]. We showed here that the frequency of viable integrants of lcc pDNA vector into the circular prokaryotic $E$. coli genome is reduced at least five orders of magnitude compared to its ccc counterpart. The lethal effect of chromosomal disruption in $E$. coli was investigated by site-specific insertion of the lcc integrating pDNA vector using Int-att $B$ systems from bacteriophages $\lambda$ and $\Phi 80$. Our results linking site of chromosomal disruption to degree of lethality agree with previous work by Cui et al. (2007) who reported that the closer the linearization of the chromosome occurred to the E. coli origin of replication, the stronger was the observed growth defect [36]. Our microscopy results indicated a dramatic reduction in cell size and surrounding cellular debris following genome disruption, which we attribute to replication inhibition and associated cellular stress, phenotypes we are presently investigating further in bacterial and mammalian cells. The generation of filamentous cells similarly may be due to SOS-independent filamentation arising from inhibited or dramatically slowed replication [36].

Considering the lethal effect of lcc DNA vector integration into host chromosome, lcc based gene replacement vectors will likely provide a safer option for targeted recombination events. We report elsewhere that lcc vector integration into human cells results in chromosomal disruptions and cell death, preventing propagation of the lcc vector-integrated cell and its natural elimination from the transfected cell population. As such, mini lcc vectors potentially serve as ideal choice for knock-in and gene replacement studies in stem and other pluripotent cells for the generation of transgenic plant and animal models and regenerative medicine, avoiding damage and side effects of integration.

\section{Conclusion}

Mini lcc DNA vector constructs were generated in vivo exploiting the bacteriophage PY54-derived Tel-pal recombination system in a conditional recombinase expression scheme. The mini lcc DNA vectors provide a safer alternative to conventional pDNA vectors without compromising utility. In addition to a unique multitarget sequence, each vector is equipped with two SV40 enhancer sequences at the two covalently closed ends of the linear plasmids to facilitate the nuclear uptake and enhance the transfection efficiency and expression of the GOI. The production system reported here and its associated safety profile may serve as a basis for simplified, scalable, and safer DNA vector production that could drive the design of virtually limitless innovations with applications to health, agriculture, and industry.

\section{Methods}

\section{Strains and plasmids}

E. coli $\mathrm{K}-12$ strains were used in the generation of all recombinant cell constructs and DH5 $\alpha$ and JM109, in particular, were employed as hosts for plasmid constructions and amplification.

A list of bacterial and phage strains used in this study are shown in Table 1.

\section{Construction of Recombinant Cells (R-cells)}

W3110 was used for chromosomal engineering studies and in vivo recombinase expression as follows. Protelomerase coding gene tel was amplified from bacteriophage PY54 lysate using the following primers: Tel-F 5'-GCGGATCCTGGGT TACT T TAATTTGTGTGTT-3' and Tel-R 5'-CGCTCGAGTTACTCCATATTTTCAGT CCATGCTTGT-3' (annealing $\mathrm{Tm} 64^{\circ} \mathrm{C}$ ). Protelomerase coding gene telN was amplified from bacteriophage N15 lysate using primers: TelN-F $5^{\prime}$-ATCGGATCCC GATATCCAGAGACTTAGAAACGGG-3' and TelN-R 5' - ATATAAAGCTTCTTTTAGCTGTAGTACGTTTCC CATGCG-3 $3^{\prime}$ (annealing $\operatorname{Tm} 62^{\circ} \mathrm{C}$ ). As a positive control for in vivo production of modified DNA vectors, the recombinase encoding gene cre was amplified from bacteriophage P1rev6 lysate using primers: Cre-F 5'GGAATTCCGGTCGCTGGCGTTTCTATGAC-3' and Cre-R $\quad 5^{\prime}$-CGCTCGAGTGAATATTAGTGCTTACAGA CAG-3' (annealing $\mathrm{Tm} 66^{\circ} \mathrm{C}$ ). Italicized regions denote restriction sites for BamHI, XhoI, HindIII, and EcoRI. PCR amplifications were conducted using Phusion Flash High-Fidelity PCR Master Mix (New England Biolabs) for $30 \mathrm{~s}$ at $98^{\circ} \mathrm{C}$ for initial denaturation, 30 cycles of $5 \mathrm{~s}$ at $98^{\circ} \mathrm{C}, 10 \mathrm{~s}$ at annealing $\mathrm{Tm}, 45 \mathrm{~s}$ at $72^{\circ} \mathrm{C}$, and $2 \mathrm{~min}$ at $72^{\circ} \mathrm{C}$ for final extension to generate cre $(1.3 \mathrm{~kb})$, tel $(2.1 \mathrm{~kb})$, and telN $(2.3 \mathrm{~kb})$ fragments. Constructs were tested and confirmed by colony PCR and analytical digestion. PCR products were purified 
from $0.8 \%$ agarose gel (Qiagen Gel extraction kit), and digested with the listed enzymes (New England Biolabs). Recombinase genes were cloned into the MCS of the inducible prokaryotic expression plasmid vector pPL451 (Accession \#AB248919) to produce pNN1, pNN2, and pNN3 vectors. pPL451 (4.2 kb) imparts temperatureregulated expression of the cloned gene via $\mathrm{CI}[\mathrm{Ts}] 857$ mediated repression of the $\lambda p L$ strong promoter. A list of plasmids used or constructed in this study is shown in Table 1. All primers were designed using the Gene Runner 3.01 (Hastings Software, Inc) and synthesized commercially (Sigma-Aldrich, Inc). R-cells were constructed via insertion of recombinase genes into $E$. coli W3110 chromosome using the pBRINT-cat integrating plasmids, which facilitate the homologous recombination and chromosomal integration of cloned sequence of interest into the lacZ gene of E. coli [37]. For each plasmid construct encoding inducible expression of a cloned recombinase in pPL451, the $c$ I857- $P_{L}-X-t_{L}$ cassette (where $\mathrm{X}=$ cre, tel or telN) was amplified from the pNN1 to 3 constructs by the cI857X-F $5^{\prime}$-TCCCCGCG GAGCTATGACCATGATTACGAATTGC-3' ${ }^{\prime}$, cI857telN/ cre-R 5'-GGACTAGTCCCCATTCAGGCTGCGCAAC TGTTG-3', and cI857tel-R 5'-GCTCTAGAGCAG GCTGCGCAACTGTTGGGAAG- $3^{\prime}$ primers with SacII, SpeI, and $\mathrm{XbaI}$ sites respectively. The amplified cassettes were cloned into the MCS of pBRINT $\left(\mathrm{Cm}^{\mathrm{R}}\right)$ integrating plasmid to produce pNN4, pNN5, and pNN6 integrating pDNA constructs. Amplification have been performed by the Phusion Flash High-Fidelity PCR Master Mix (New England Biolabs) for $10 \mathrm{~s}$ at $98^{\circ} \mathrm{C}$ for initial denaturation, 30 cycles of $1 \mathrm{~s}$ at $98^{\circ} \mathrm{C}, 5 \mathrm{~s}$ at $68^{\circ} \mathrm{C}, 120 \mathrm{~s}$ at $72^{\circ} \mathrm{C}$, and 1 $\mathrm{min}$ at $72^{\circ} \mathrm{C}$ for final extension to generate cl857-cre $(2.8$ $\mathrm{kb})$, cI857-tel (3.2 kb), and cI857-telN (3.5 kb) fragments. Constructs were tested and confirmed by colony PCR and analytical digestion.

E. coli cells were grown in Luria-Bertani (LB) medium and plated on LB-Agar plates composed of 1.0\% Tryptone, $0.5 \%$ Yeast Extract, $1.0 \% \mathrm{NaCl}, \mathrm{pH} 7.0$. Antibiotics (Ab) (Sigma-Aldrich, Inc) were used at the following concentrations for the growth of cells carrying multicopy plasmids: ampicillin (Ap, $100 \mu \mathrm{g} / \mathrm{ml}$ in $\mathrm{H}_{2} \mathrm{O}$ ), chloramphenicol $(\mathrm{Cm}, 25 \mu \mathrm{g} / \mathrm{ml}$ in isopropanol), gentamycin ( $\mathrm{Gm}, 15 \mu \mathrm{g} / \mathrm{ml}$ in $\mathrm{H}_{2} \mathrm{O}$ ), and kanamycin $(\mathrm{Km}, 50 \mu \mathrm{g} / \mathrm{ml}$ in $\mathrm{H}_{2} \mathrm{O}$ ). $\mathrm{H}_{2} \mathrm{O}$ used for dilution of primers, plasmids, antibiotics, and production of competent cells is nuclease-free sterile molecular grade water (SigmaAldrich, Inc). To achieve chromosomal integration of the pNN4 to 6 constructs into $\operatorname{Rec}^{+}$W3110, a 1:100 dilution of fresh overnight cells was grown on SOB media (2.0\% Tryptone, $0.5 \%$ Yeast Extract, $2.0 \% \mathrm{NaCl}, 1.0 \% \mathrm{KCl}$, $1.0 \% \mathrm{MgCl}_{2}$, and $\left.1.0 \% \mathrm{MgSO}_{4}\right)$ at $37^{\circ} \mathrm{C}$ to $\mathrm{A}_{600}=0.4-0.6$ and cells were harvested by centrifugation at $5 \mathrm{~K}$ RPM for $5 \mathrm{~min}$. Cells were washed in water three times and W3110 cells were transformed by $1 \mu \mathrm{g}$ of pNN4, 5 , or 6 integrating vectors via electroporation at $800 \mathrm{v}$. Cells were recovered in SOC (SOB with $2.0 \%$ Glucose) at $30^{\circ} \mathrm{C}$ for $1 \mathrm{~h}$, then spread onto selective media on $12.5 \mu \mathrm{g} / \mathrm{ml}$ of chloramphenicol, $100 \mu \mathrm{g} / \mathrm{ml}$ of 5-bromo-4-chloro-indolyl- $\beta$-Dgalactopyranoside (X-Gal) (Promega), and $0.1 \mathrm{mM}$ of Isopropyl $\beta$-D-1-thiogalactopyranoside (IPTG) (SigmaAldrich, Inc) added to LB agar plates and incubated overnight at $30^{\circ} \mathrm{C}$. To make a $50 \mathrm{mg} / \mathrm{ml}$ stock solution, $500 \mathrm{mg} \mathrm{X}$-Gal were dissolved in $10 \mathrm{ml}$ dimethylformamide. Protect plates from light. White colonies were selected and further screened for sensitivity to ampicillin and chloramphenicol. White $\mathrm{Ap}^{\mathrm{S}}$ colonies indicated loss the $\mathrm{pNN}$ integrating plasmids after disruptive insertion of the $c 1857-P_{L}-X-t_{L}$ cassette into the lacZ gene, generating recombinant derivatives, $W 1 \mathrm{NN}, \mathrm{W} 2 \mathrm{NN}$, and W3NN (Table 1). W3110 [lacZ::cat- cl857(cre/tel/telN)] recombinants were confirmed for presence of the cI857$P_{L}-X-t_{L}$ cassette and temperature-regulated, conditional expression of recombinanse, by colony PCR using Taq polymerase enzyme (NEB), sequencing (Sigma), and SDS PAGE (BioRad) at various temperatures between $30^{\circ} \mathrm{C}$ and $42^{\circ} \mathrm{C}$. For the selection of cells carrying the antibiotic selection markers integrated in the chromosome, the following concentrations were used: $\mathrm{Cm}(12.5$ $\mu \mathrm{g} / \mathrm{ml}), \mathrm{Gm}(5 \mu \mathrm{g} / \mathrm{ml})$, and $\mathrm{Km}(20 \mu \mathrm{g} / \mathrm{ml})$.

\section{Construction of modified/ new generation of pDNA Vectors}

The multi-purpose target site, named Super Sequence (SS), was designed to carry Cre, Flp and TelN minimal targets sites (loxP-FRT-telRL) respectively, all within the Tel 142 bp target site, pal. SS also carries a 78 bp SV40 enhancer sequence that flanks each side of the pal sequence to facilitate nuclear translocation and enhancing transfection efficiency. The SS fragment was synthesized by the GeneScript and cloned into the pUC57 by EcoRI and HindIII. Commercial eukaryotic expression plasmid vector, pGL2-promoter (5.8 kb) (Promega), was modified by replacement of the luc gene $(1.65 \mathrm{~kb})$ with egfp (790 bp) from pGFP (Clontech, Inc.) to form pNN7 (Genescript, Inc.) (4.9 kb) Next, SS was cloned immediately upstream of the SV40 promoter + intron site of pNN7 to form pNN8 $(5.3 \mathrm{~kb})$. Then the SS fragment was cloned downstream of the poly A site of pNN8 to form pNN9 (5.6 kb). The multi-copy pDNA vector pNN9 carries 2 SS sites that flank the egfp gene cassette and can be converted to a "minicircle" DNA vector (mediated by Cre-loxP; Flp-FRT), or a mini linear covalently closed DNA vector (mediated by TelN-telRL; Tel-pal). R-cells were transformed by $1 \mu \mathrm{g}$ of pNN7 to 9 DNA constructs on $\mathrm{LB}+\mathrm{Ap}(50 \mu \mathrm{g} / \mathrm{ml})$ to $\mathrm{A}_{600}=$ 0.6 at $30^{\circ} \mathrm{C}$ with aeration. To induce recombinase expression and plasmid conformational conversion, 
transformed R-cells were heat shocked to induce the recombinase expression at $42^{\circ} \mathrm{C}$ for $30 \mathrm{~min}$ at midlogarithmic phase of bacterial growth, before being transferred to $30^{\circ} \mathrm{C}$ overnight. Cells were then harvested and plasmid extracted (Omega kit, VWR). Plasmid topology was assayed by agarose gel electrophoresis and digestion. Standard recombinant DNA techniques were performed as described by Sambrook et al. (1989).

\section{Chromosomal Integration Assays of Linear Covalently Closed (LCC) DNA}

"CRIM (conditional-replication, integration, and modular)" integrating plasmids [25] that possess a R6K origin of replication and a phage attachment (attP) site were modified to carry the SS fragment. SS was cloned into the pAH120 and pAH153 constructs (from NBRP; Table 1) by ClaI and BamHI (New England Biolabs) to generate the pNN10 (3.3 kb) and pNN11 (2.6 kb) constructs, respectively. Plasmids were integrated into the host bacterial attachment $(a t t B)$ site by supplying phage integrase (Int) from the helper plasmids. Plasmid pNN10 and pNN11 constructs were amplified in $\mathrm{DH} 5 \alpha(\lambda$ pir $)$ or BW23474, and the successful clones were confirmed by restriction pattern digestion and colony PCR. Int helper plasmids pINT-ts $(\lambda$ int) and pAH123 (Ф80 int) that express int from $\lambda p L$ under $\mathrm{CI}[\mathrm{Ts}] 857$ control and carry a temperature sensitive pSC101 ori were used for integration of CRIM, pNN10 and pNN11 plasmids into their corresponding chromosomal attB sites of pir- hosts that are non-permissive for plasmid replication.

R-Cells W1NN, W2NN, and W3NN (Table 1) W3110 [lacZ::cat-cI857(cre/tel/telN)] were grown in $2 \mathrm{ml}$ of $\mathrm{SOB}$ cultures at $30^{\circ} \mathrm{C}$ to an optical density of $\mathrm{A}_{600}=0.6$ and then electroporated and transformed by $50 \mathrm{ng}$ helper plasmids pINT-Ts $(\lambda$ int) or pAH123 (Ф80 int) and selected on $\mathrm{LB}+$ ampicillin agar at $30^{\circ} \mathrm{C}$. R-Cells carrying helper plasmids were grown in $50 \mathrm{ml}$ of $\mathrm{SOB}+$ ampicillin at $30^{\circ} \mathrm{C}$ to $\mathrm{A}_{600}=0.6$ then transformed by 1 $\mu \mathrm{g}$ of pAH120, pNN10 (pAH120+SS), pAH153, pNN11 (pAH153+SS) DNA, suspended in SOC at $37^{\circ} \mathrm{C}$ for $1 \mathrm{~h}$ for recovery and Int expression and at $42^{\circ} \mathrm{C}$ for $30 \mathrm{~min}$ for lose of helper plasmid, then selected on LB + antibiotic $(15 \mu \mathrm{g} / \mathrm{ml} \mathrm{Km}$ for pAH120, pNN10 and $5 \mu \mathrm{g} / \mathrm{ml}$ Gm for pAH153, pNN11) and incubated overnight at $37^{\circ} \mathrm{C}$. Positive bacterial growth on selective media (15 $\mu \mathrm{g} / \mathrm{ml} \mathrm{Km}$, or $5 \mu \mathrm{g} / \mathrm{ml} \mathrm{Gm}$ ) and negative bacterial growth on ampicillin media represents stable integration of the gene of interest and loss of the helper Int expression plasmid. Single-copy integrants W4NN to W15NN represent the $\mathrm{SS}^{+}$pAH120 (pNN10), $\mathrm{SS}^{-} \mathrm{pAH} 120, \mathrm{SS}^{+}$ pAH153 (pNN11), and SS ${ }^{-}$pAH153 pDNA integrated into the W3110 or W3110 [lacZ::cat-cI857(cre/tel/telN)]) were screened and selected by PCR using predesigned primers [25].

\section{Viability Assays of Linear Covalently Closed (LCC) DNA integration}

Single copy pAH120, pNN10 (pAH120+SS), pAH153, pNN11 (pAH153+SS) DNA integrants W4NN to W15NN were isolated on selective media.

Integrants were grown in $2 \mathrm{ml} \mathrm{LB}$ media + selective antibiotic at $30^{\circ} \mathrm{C}$ to an optical density of $\mathrm{A}_{600}=0.4$ and then divided into two groups of $1 \mathrm{ml}$ each and grown to $\mathrm{A}_{600}=1$. The first group was grown at $30^{\circ} \mathrm{C}$ with repressed cre/tel/tel $N$ expression and the second group was grown at $42^{\circ} \mathrm{C}$, induced for cre/tel/telN expression. Cells were spread on selective plated and grew overnight at $30^{\circ} \mathrm{C}$ and $42^{\circ} \mathrm{C}$, respectively. Viability was assayed by colony counting and size of the colonies grew at $30^{\circ} \mathrm{C}$ versus $42^{\circ} \mathrm{C}$.

\section{Visualization of cells}

Cells were visualized by gram staining as previously described [38]. Briefly, integrated cells were grown in 2 $\mathrm{ml}$ of LB media + selective antibiotic from freshly grown cells at $30^{\circ} \mathrm{C}$ to early log phase $\mathrm{A}_{600}=0.2$ and then were divided in two tubes and grown at $30^{\circ} \mathrm{C}$ and $42^{\circ} \mathrm{C}$ to late $\log$ phase, $\mathrm{A}_{600}=0.8$. Bacterial smears were then prepared on the slide and heat fixed and gram stained. Pictures of bacteria were taken at $1000 \mathrm{X}$ magnification. From pictures, 400 random cells were chosen for measurement under all tested conditions.

\section{Abbreviations}

Bp: Base pair(s); CCC: Circular covalently closed; DTS: DNA nuclear targeting sequence; GOI: Gene of interest; IF: Integration frequency; kb: Kilo-base(s); kDa: KiloDalton(s); LB: Luria-Bertani medium; LCC: Linear covalently closed; MCS: Multiple cloning site(s); MIDGE: Minimalistic immunogenic defined gene expression; NLS: Nuclear localization signal; NPC: Nuclear membrane pore complex; o: Operator; PAGE: Polyacrylamide gel electrophoresis; pDNA: Plasmid DNA; p: Promoter; protelomerase: Prokaryotic telomerase; R: Recombinant cells; SDS: Sodium dodecyl sulfate; SS: Super Sequence; [ ]: Denotes plasmid-carrier state.

\section{Competing interests}

The authors declare that there is no conflict of interests in the submission of this manuscript.

\section{Authors' contributions}

NN conducted the experimental work and significantly toward the design and writing of this manuscript. RAS designed the system described here and contributed significantly to the direction of the project and writing of the manuscript. Both authors read and approved the final manuscript.

\section{Authors' information}

RAS is currently an Assistant Professor of Pharmaceutical Science at University of Waterloo, School of Pharmacy and SDM Professor of Business and Entrepreneurship. NN is currently a PhD candidate at University of Waterloo.

\section{Acknowledgements}

This work was supported by UW Start-up funds to RAS; and Drug Safety and Effectiveness Cross-Disciplinary Training (DSECT) Scholarship provided by Canadian Institute of Health Research (CIHR), Ontario Graduate Scholarship (OGS), and Waterloo Institute of Nanotechnology (WIN) fellowship to NN. The authors also want to thank Gary Tran for his assistance in generating the pNN1 construct.

Received: 2 October 2012 Accepted: 25 November 2012 Published: 6 December 2012 


\section{References}

1. Branca MA: Gene therapy: cursed or inching towards credibility? Nat Biotechnol 2005, 23:519-521.

2. Miller AM, Dean DA: Tissue-specific and transcription factor-mediated nuclear entry of DNA. Adv Drug Deliv Rev 2009, 61:603-613.

3. Vidal M, Hoekstra D: In vitro fusion of reticulocyte endocytic vesicles with liposomes. J Biol Chem 1995, 270:17823-17829.

4. Vaysse L, Gregory LG, Harbottle RP, Perouzel E, Tolmachov O, Coutelle C: Nuclear-targeted minicircle to enhance gene transfer with non-viral vectors in vitro and in vivo. J Gene Med 2006, 8:754-763.

5. Chahine MN, Pierce GN: Therapeutic targeting of nuclear protein import in pathological cell conditions. Pharmacol Rev 2009, 61:358-372.

6. Zanta MA, Belguise-Valladier P, Behr J-P: Gene delivery: A single nuclear localization signal peptide is sufficient to carry DNA to the cell nucleus. Proc Natl Acad Sci 1999, 96:91-96.

7. Tanimoto M, Kamiya H, Minakawa N, Matsuda A, Harashima H: No enhancement of nuclear entry by direct conjugation of a nuclear localization signal peptide to linearized DNA. Bioconjug Chem 2003, 14:1197-1202.

8. Spies B, Hochrein H, Vabulas M, Huster K, Busch DH, Schmitz F, Heit A, Wagner $\mathrm{H}$ : Vaccination with plasmid DNA activates dendritic cells via Toll-Like Receptor 9 (TLR9) but functions in TLR9-deficient mice. J Immunol 2003, 171:5908-5912.

9. Darquet A-M Rangara R, Kreiss P, Schwartz B, Naimi S, Delaère P, Crouzet J, Scherman D: Minicircle: an improved DNA molecule for in vitro and in vivo gene transfer. Nature 1999, 6:209-218.

10. Mayrhofer $P$, Schleef $M$, Jechlinger $W$ : Use of minicircle plasmids for gene therapy. In Gene Therapy of Cancer. Edited by Walther W, Stein U.: Human Press; 2009:87-104 [Springer Protocols: Methods in Molecular Biology. Volume 542].

11. Faurez F, Dory D, Le Moigne V, Gravier R, Jestin A: Biosafety of DNA vaccines: New generation of DNA vectors and current knowledge on the fate of plasmids after injection. Vaccine 2010, 28:3888-3895.

12. Prazeres DMF: Plasmid Biopharmaceuticals: basics, application, and manufacturing. New Jersey: Wiley; 2011.

13. Rodríguez EG: Nonviral DNA vectors for immunization and therapy: design and methods for their obtention. J Mol Med 2004, 82:500-509.

14. López-Fuertes L, Pérez-Jiménez E, Vila-Coro AJ, Sack F, Moreno S, Konig SA Junghans C, Wittig B, Timon M, Esteban M: DNA vaccination with linear minimalistic (MIDGE) vectors confers protection against Leishmania major infection in mice. Vaccine 2002, 21:247-257.

15. Schakowski FGM, Junghans C, Schroff M, Buttgereit P, Ziske C, Schöttker B, König-Merediz SA, Sauerbruch T, Wittig B, Schmidt-Wolf IG: A novel minimal-size vector (MIDGE) improves transgene expression in colon carcinoma cells and avoids transfection of undesired DNA. Mol Ther 2001, 5:3793-3800.

16. Schakowski F, Gorschluter M, Buttgereit $P$, Märten A, Lilienfeld-Toal MV, Junghans C, Schroff M, König-Merediz SA, Ziske C, Strehl J, Sauerbruch T, Wittig B, Schmidt-Wolf IG: Minimal size MIDGE vectors improve transgene expression in vivo. In Vivo 2007, 21:17-23.

17. Valentin N, Rybchin ANS: The plasmid prophage N15: a linear DNA with covalently closed ends. Mol Microbiol 1999, 33:895-903.

18. Deneke J, Ziegelin GN, Lurz R, Lanka E: The protelomerase of temperate Escherichia coli phage N15 has cleaving-joining activity. Proc Natl Acad Sci U S A 2000, 97:7721-7726.

19. Grigoriev PS, Lobocka M: Determinants of segregational stability of the linear plasmid-prophage N15 of Escherichia coli. Mol Microbiol 2001, 42:355-368

20. Heinrich J, Schultz J, Bosse M, Ziegelin G, Lanka E, Moelling K: Linear closed mini DNA generated by the prokaryotic cleaving-joining enzyme TeIN is functional in mammalian cells. J Mol Med 2002, 80:648-654.

21. Stefan H, Iris K, Rudi L, Erich L, Bernd A: PY54, a linear plasmid prophage of Yersinia enterocolitica with covalently closed ends. Mol Microbiol 2003 48:989-1003.

22. Chen Q, Narayanan K: Crude protein extraction protocol for phage N15 protelomerase in vitro enzymatic assays. Anal Biochem 2011, 414:169-171.

23. Sauer B, Henderson N: Site-specific DNA recombination in mammalian cells by the Cre recombinase of bacteriophage P1. Proc Natl Acad Sci $1988,85: 5166-5170$
24. Wang $Y$, Krushel LA, Edelman GM: Targeted DNA recombination in vivo using an adenovirus carrying the cre recombinase gene. Proc Natl Acad Sci 1996, 93:3932-3936.

25. Haldimann A, Wanner BL: Conditional-replication, integration, excision, and retrieval plasmid-host systems for gene structure-function studies of bacteria. J Bacteriol 2001, 183:6384-6393.

26. Dürrschmid K, Reischer H, Schmidt-Heck W, Hrebicek T, Guthke R, Rizzi A, Bayer $\mathrm{K}$ : Monitoring of transcriptome and proteome profiles to investigate the cellular response of $E$. coli towards recombinant protein expression under defined chemostat conditions. J Biotechnol 2008, 135:34-44.

27. Shatzman AR, Gross MS, Rosenberg M: Expression using vectors with phage $\lambda$ regulatory sequences. Curr Protoc Mol Biol 2001, Chapter 16:Unit 16.3 .

28. Srivastava IK, Singh M: DNA vaccines: Focus on increasing potency and efficacy. Int J Pharm Med 2005, 19:15-28.

29. Jia F, Wilson KD, Sun N, Gupta DM, Huang M, Li Z, Panetta NJ, Chen ZY, Robbins RC, Kay MA, Longaker MT, Wu JC: A nonviral minicircle vector for deriving human iPS cells. Nat Methods 2010, 7:197-199.

30. Luke JM, Vincent JM, Du SX, Gerdemann U, Leen AM, Whalen RG, Hodgson CP, Williams JA: Improved antibiotic-free plasmid vector design by incorporation of transient expression enhancers. Gene Ther 2011, 18:334-343

31. Klinman DM, Yi AK, Beaucage SL, Conover J, Krieg AM: CpG motifs present in bacteria DNA rapidly induce lymphocytes to secrete interleukin 6, interleukin 12, and interferon gamma. Proc Natl Acad Sci 1996, 93:2879-2883.

32. Catanese DJ Jr, Fogg JM, Schrock DE II, Gilbert BE, Zechiedrich L: Supercoiled minivector DNA resists shear forces associated with gene therapy delivery. Gene Ther 2012, 19:94-100.

33. Chen Z-Y, He C-Y, Ehrhardt A, Kay MA: Minicircle DNA vectors devoid of bacterial DNA result in persistent and high-level transgene expression in vivo. Mol Ther 2003, 8:495-500.

34. Baum C, von Kalle C, Staal FJT, Li Z, Fehse B, Schmidt M, Weerkamp F, Karlsson S, Wagemaker G, Williams DA: Chance or necessity? Insertional mutagenesis in gene therapy and its consequences. Mol Ther 2004, 9:5-13.

35. Hacein-Bey-Abina S, von Kalle C, Schmidt M, Le Deist F, Wulffraat N, McIntyre E, Radford I, Villeval J-L, Fraser CC, Cavazzana-Calvo M, Fischer A: A serious adverse event after successful gene therapy for X-linked severe combined immunodeficiency. N Eng J Med 2003, 348:255-256.

36. Cui T, Moro-oka N, Ohsumi K, Kodama K, Ohshima T, Ogasawara N, Mori H, Wanner B, Niki H, Horiuchi T: Escherichia coli with a linear genome. EMBO Rep 2007, 8:181-187.

37. Le Borgne S, Palmeros Bl, Valle F, Bolivar F, Gosset G: pBRINT-Ts: a plasmid family with a temperature-sensitive replicon, designed for chromosomal integration into the lacZ gene of Escherichia coli. Gene 1998, 223:213-219.

38. Cappuccino JG, Natalie S: Microbiology: A laboratory manual: BenjaminCummings Publishing Company; 2013. ISBN -13: 978-0321840226.

39. Andreas S, Schwenk F, Küter-Luks B, Faust N, Kuhn R: Enhanced efficiency through nuclear localization signal fusion on phage PhiC31-integrase: activity comparison with Cre and FLPe recombinase in mammalian cells. Nucleic Acids Res 2002, 30:2299-2306.

40. Kvitko B, Bruckbauer S, Prucha J, McMillan I, Breland E, Lehman S, Mladinich K, Choi K-H, Karkhoff-Schweizer R, Schweizer H: A simple method for construction of pir+ Enterobacterial hosts for maintenance of R6K replicon plasmids. BMC Res Notes 2012, 5:157.

41. Bachmann BJ: Pedigrees of some mutant strains of Escherichia coli K-12. Bacteriol Rev 1972, 36:525-557.

42. Kaur T, Al Abdallah Q, Nafissi N, Wettig S, Funnell BE, Slavcev RA: ParAB-mediated intermolecular association of plasmid P1 parS Sites. Virology 2011, 421:192-201.

43. Love CA, Lilley PE, Dixon NE: Stable high-copy-number bacteriophage $\lambda$ promoter vectors for overproduction of proteins in Escherichia coli. Gene 1996, 176:49-53.

doi:10.1186/1475-2859-11-154

Cite this article as: Nafissi and Slavcev: Construction and

Characterization of an in-vivo Linear Covalently Closed DNA Vector Production System. Microbial Cell Factories 2012 11:154. 